\title{
Correction to: Pathological impact of transanal colorectal tube for obstructive colorectal cancer
}

\author{
Yusuke Okuda ${ }^{1,2} \cdot$ Takaya Shimura $^{1}$ (D) $\cdot$ Hiroyuki Kato $^{3} \cdot$ Tomonori Yamada $^{4} \cdot$ Yoshikazu Hirata $^{2} \cdot$ Makoto Natsume $^{1}$. \\ Hiroyasu Iwasaki ${ }^{1} \cdot$ Ryuzo Yamaguchi $^{5} \cdot$ Eiji Sakamoto $^{6} \cdot$ Satoru Takahashi $^{3} \cdot$ Hiromi Kataoka $^{1}$
}

Published online: 28 October 2019

(C) Springer Science+Business Media, LLC, part of Springer Nature 2019

\section{Correction to: Surgical Endoscopy} https://doi.org/10.1007/s00464-019-07188-w

In Methods of Abstract, the word "2015" should be changed to " 2011 ".

Publisher's Note Springer Nature remains neutral with regard to jurisdictional claims in published maps and institutional affiliations.

The original article can be found online at https://doi.org/10.1007/ s00464-019-07188-w.

Takaya Shimura

tshimura@med.nagoya-cu.ac.jp

1 Department of Gastroenterology and Metabolism, Nagoya City University Graduate School of Medical Sciences, 1-Kawasumi, Mizuho-cho, Mizuho-ku, Nagoya 467-8601, Japan

2 Department of Gastroenterology, Kasugai Municipal Hospital, 1-1-1 Takaghi-cho, Kasugai 486-8510, Japan

3 Department of Experimental Pathology and Tumor Biology, Nagoya City University Graduate School of Medical Sciences, 1-Kawasumi, Mizuho-cho, Mizuho-ku, Nagoya 467-8601, Japan

4 Department of Gastroenterology, Japanese Red Cross Nagoya Daini Hospital, 2-9 Myoken-cho, Showa-ku, Nagoya 466-8650, Japan

5 Department of Surgery, Kasugai Municipal Hospital, 1-1-1 Takaghi-cho, Kasugai 486-8510, Japan

6 Department of Surgery, Japanese Red Cross Nagoya Daini Hospital, 2-9 Myoken-cho, Showa-ku, Nagoya 466-8650, Japan 